Research Article

\title{
A Study to Assess the Effectiveness of Structured Teaching Programme on Knowledge regarding Management of Selected Obstetric Emergencies among B.Sc. Nursing $3^{\text {rd }}$ Year Students of Bibi Halima College of Nursing and Medical Technology Srinagar Kashmir
}

\author{
Ulfat Rashid', Muneera Bashir ${ }^{2}$
}

${ }^{1}$ M.Sc.Nursing (Obstetrical and Gynecological Nursing) Student, ${ }^{2}$ Associate Professor, Madr-e-Maherbaan Institute of Nursing Sciences Research SKIMS, Soura Srinagar, Jammu and Kashmir, India.

DOI: https://doi.org/10.24321/2455.9318.202023

\section{I $\quad \mathbf{N} \quad \mathbf{F} \quad \mathbf{O}$}

\section{Corresponding Author:}

Ulfat Rashid, Madr-e-Maherbaan Institute of Nursing Sciences Research SKIMS, Soura Srinagar, Jammu and Kashmir, India.

E-mail Id:

rashidulfat398@gmail.com

Orcid Id:

https://orcid.org/0000-0003-4023-9123

How to cite this article:

Rashid U, Bashir M. A Study to Assess the Effectiveness of Structured Teaching Programme on Knowledge regarding Management of Selected Obstetric Emergencies among B.Sc. Nursing $3^{\text {rd }}$ Year Students of Bibi Halima College of Nursing and Medical Technology Srinagar Kashmir. Int J Nurs Midwif Res 2020; 7(3): 31-35.

Date of Submission: 2020-11-04

Date of Acceptance: 2020-12-28

\section{$\begin{array}{llllllll}\text { A } & \text { B } & \mathbf{S} & \mathbf{T} & \mathbf{R} & \mathbf{A} & \mathbf{C} & \mathbf{T}\end{array}$}

Obstetric emergencies are life threatening medical conditions of serious and often dangerous in nature, developing suddenly and unexpectedly during pregnancy, labor or after delivery and demanding immediate attention in order to save life of mother and baby. A pre-experimental one group pre-test post-test design was used to conduct a study on BSc nursing 3rd year students at Bibi Halima College of Nursing and Medical Technology Srinagar Kashmir to determine the effectiveness on knowledge regarding Management of Selected Obstetric Emergencies. In the present study non-probability purposive sampling technique was used. The findings of the study revealed that majority of study subjects (70\%) had average knowledge, $30 \%$ had Poor knowledge and none of the study subjects had good knowledge regarding management of selected obstetric emergencies in pre-test. In post-test majority of the study subjects (88\%) had good knowledge, and least (12\%) had average knowledge and none of the study subjects had poor knowledge regarding management of selected obstetric emergencies. The mean post-test knowledge level $(53.2 \pm 0.83)$ was higher than the mean pre-test knowledge level $(25.7 \pm 0.956)$, which indicates the effectiveness of structured Teaching Programme in increasing the level of knowledge of BSc nursing 3rd year students regarding management of selected obstetric emergencies at 0.05 level of significance. There was no statistically significant association between pre-test knowledge level and demographic variables like gender, residence and any previous exposure at $p<0.05$. The findings of the study concluded that Study subjects didn't possess adequate knowledge regarding management of selected obstetric emergencies in pre-test so there was dire need to enhance their knowledge regarding management of obstetric emergencies.

Keywords: Obstetric Emergencies, Effectiveness, Structured Teaching Programme 


\section{Introduction}

Obstetrical emergencies are life threatening situations in obstetrics or midwifery practice which are unexpected, develop rapidly, and are often fatal for the women and fetus. Death of the mother due to obstetric emergencies was common during early $20^{\text {th }}$ century. ${ }^{1}$ No specialty of medicine is more inundated with emergencies than obstetrics. There are a number of illnesses and disorders of pregnancy that can threaten the well-being of both mother and child. The obstetrical emergencies in pregnancies include ectopic pregnancy, placenta previa, placenta abruption, pre-eclampsia, eclampsia and premature rupture of membrane. Obstetric emergencies during labor include amniotic fluid embolism, acute inversion of uterus, and rupture of uterus, placenta accrete, prolapsed umbilical cord and shoulder dystocia. And obstetric emergencies after delivery include post -partum hemorrhage and shock. Around $15 \%$ of all pregnant women develop a potentially life-threatening complication that calls for skilled care, and some require a major obstetrical intervention to survive. About 830 women die from pregnancy or childbirth-related complications around the world every day, of these, $99 \%$ of which occur in the developing countries majority (80\%) of these deaths are preventable. ${ }^{2}$

In every country mothers and children constitute a major segment of the total population. Therefore a service to women during pregnancy and delivery is tremendously significant in health care delivery system. Worldwide nearly 600,000 women between the age of 15 and 49 die every Year, due to complications arising from pregnancy and childbirth. This means almost every minute of every year, there is a maternal death. ${ }^{3}$ The maternal mortality ratio in developing countries in 2015 is 239 per 100000 live births versus 12 per 100000 live births in developed countries. ${ }^{4}$ As stated by the WHO in 2005 World Health Report "Make Every Mother and Child Count". Obstetric emergencies are responsible for $70.6 \%$ of the maternal mortality and $86 \%$ of the perinatal mortality within the period. ${ }^{5}$ Obstetrical hemorrhage is the leading cause of maternal and perinatal mortality and morbidity. It comprises $46 \%$ of maternal mortality worldwide. Indian Maternal Mortality rate currently is $174 / 1000$ live births. ${ }^{6}$

According to a survey about 6,000 mothers die during childbirth and due allied complications of pregnancy in Kashmir, Jammu and Kashmir has a maternal mortality rate of 2400, which is the highest MMR in the world. ${ }^{7}$

As per a study conducted by the team of Jha M8 from center for Disease control and prevention, of 5, 476, 970 population in four districts, it was shown that 357 women of reproductive age (15-49) died and 154 died of complications during pregnancy, child birth or the puerperal period. Maternal Mortality Rate (MMR) in those four districts was 418 in Kupwara, 774 in Anantnag, 2182 in Baramullah and 6507 in Bandipora. Baramullah district showed the highest mortality risk ever recorded in human history, with 54\% more than half of the woman of reproductive age died. According to the survey women who died post-partum were $64 \%$ within 42 days. $56 \%$ of these women died in the first 24 hours. 60\% Kashmiri's do not have access to basic health services. Even $40 \%$ Basic Package of Health Services (BPHS) offers basic emergency care in valley, only $7 \%$ have capacities to provide comprehensive emergency obstetric care according to the Ministry of Health.

\section{Objectives}

- $\quad$ To assess the pre-test knowledge level of BSc. Nursing 3rd Year students regarding the management of selected obstetric emergencies

- To assess the post-test knowledge level of BSc. Nursing $3^{\text {rd }}$ Year students regarding the management of selected obstetric emergencies

- To assess the effectiveness of structured teaching program by comparing pre-test and post-test knowledge levels

- To determine the association between pre-test knowledge level of B. Sc. Nursing $3^{\text {rd }}$ Year students with selected demographic variables (gender, residence and any previous exposure)

\section{Materials and Methods}

A pre-experimental one group pre-test post-test design was used to assess the effectiveness of structured teaching programme on knowledge regarding management of selected obstetric emergencies among BSc Nursing 3rd year students of Bibi Halima College of Nursing and Medical Technology Srinagar Kashmir. Purposive sampling technique was used to collect data from 50 study subjects who fulfilled the inclusion criteria. Data was collected using self-structured Questionnaire for collecting demographic data, and for the assessment of knowledge. The tool and the intervention were validated by a panel of experts. Tool tryout was carried out on 5 study subjects to check it for the clarity, relevance and to determine the time taken for collecting the data. Reliability co-efficient of tool was found to be 0.98 revealing the tool is consistent, precise and accurate for administration in the main study. Pilot study was conducted on 5 study subjects to assess the feasibility and practicability of the main study.

The main study was conducted among 50 study subjects from 20 th April 2019 to 28th May 2019. In the present study a self-structured Questionnaire was administered to B.Sc. nursing 3rd year students on day 1 as a pre-test 
measurement of knowledge level regarding management of selected obstetric emergencies and intervention was given in the form of Structured Teaching Programme on knowledge regarding management of selected obstetric emergencies on the same day. Post-test was conducted on day 7 after giving intervention using same self-structured questionnaire which was used in pre-test.

The data of the main study was evaluated in master data sheet and analysed by using descriptive and inferential statistics at 0.05 level of significance.

\section{Results}

Description of Demographic Variables of Study Subjects Which Include Gender, Residence and any Previous Exposure

Table I.Frequency and percentage distribution of study subjects according to gender, residence and any previous exposure

\begin{tabular}{|c|c|c|c|}
\hline \multicolumn{2}{|c|}{ (n=50) } \\
\hline \multirow{2}{*}{ Gemographic variables } & Frequency & $\begin{array}{c}\text { Percentage } \\
(\%)\end{array}$ \\
\cline { 2 - 4 } & Female & 33 & $66 \%$ \\
\hline \multirow{2}{*}{ Residence } & Mule & 17 & $34 \%$ \\
\cline { 2 - 4 } & Urban & 38 & $76 \%$ \\
\hline \multirow{2}{*}{$\begin{array}{c}\text { Any previous } \\
\text { exposure }\end{array}$} & Yes & 0 & $24 \%$ \\
\cline { 2 - 4 } & No & 50 & $0 \%$ \\
\hline
\end{tabular}

Pre-test and Post-test Knowledge Level Regarding Management of Selected Obstetric Emergencies among B.Sc. Nursing $3^{\text {rd }}$ Year Students

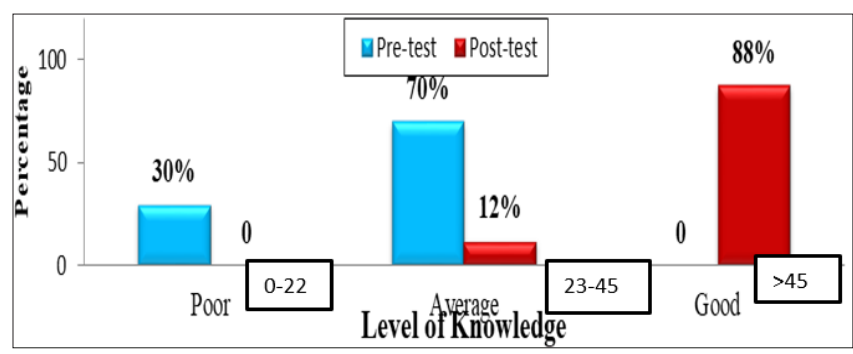

Comparison between Pre-test and Post-test Knowledge Level and the Significance of Difference between the Mean Pre-test and Mean Post-test Knowledge Level of Study Subjects regarding Management of Selected Obstetric Emergencies among B.Sc. Nursing $3^{\text {rd }}$ Year Students

The data presented in the Table 2 , showed that the mean posttest knowledge level of the study subjects on management of selected obstetric emergencies is significantly higher $(53.2 \pm 0.832)$ than that of the mean pre-test knowledge level $(25.7 \pm 0.956)$ at 0.05 level of significance hence the researcher rejects the null Hypothesis $(\mathrm{H01})$ and failed to reject the research Hypothesis $(\mathrm{H} 1)$, which states that there is significant increase in knowledge regarding management of selected obstetric emergencies among study subjects after administration of structured teaching programme at 0.05 level of significance.

Table 2.Comparison between pre-test and post-test knowledge level and significance of difference between their means

\begin{tabular}{|c|c|c|c|c|c|c|c|c|}
\hline Knowledge assessment & Mean & Median & SD & Min & Max & Mean difference & Paired ' $t$ ' test & P-value \\
\hline Pre-test & 25.7 & 26.5 & 0.956 & 6 & 42 & \multirow{2}{*}{27.5} & \multirow{2}{*}{23.47} & \multirow{2}{*}{$<0.001^{* *}$} \\
\hline Post-test & 53.2 & 54.0 & 0.832 & 40 & 63 & & & \\
\hline
\end{tabular}

Table 3.Association of pre-test knowledge level of study subjects regarding management of selected obstetric emergencies with selected demographic variables

\begin{tabular}{|c|c|c|c|c|c|c|c|c|}
\hline \multirow{2}{*}{\multicolumn{2}{|c|}{ Variable }} & \multicolumn{3}{|c|}{$\begin{array}{c}\text { Level of } \\
\text { Knowledge }\end{array}$} & \multirow{3}{*}{$\begin{array}{c}\text { Chi-square } \\
1.532 \\
\end{array}$} & \multirow{3}{*}{$\begin{array}{c}\text { p-value } \\
0.216\end{array}$} & \multirow{3}{*}{$\begin{array}{l}\text { Df } \\
1\end{array}$} & \multirow{3}{*}{$\begin{array}{c}\text { Result } \\
\text { NS* }\end{array}$} \\
\hline & & \multirow{2}{*}{$\begin{array}{c}\text { Poor } \\
7\end{array}$} & \multirow{2}{*}{$\begin{array}{c}\text { Average } \\
10\end{array}$} & \multirow{2}{*}{$\begin{array}{c}\text { Good } \\
0\end{array}$} & & & & \\
\hline Gondor & Male & & & & & & & \\
\hline Gender & Female & 8 & 25 & 0 & & & & \\
\hline \multirow{2}{*}{ Resi-dence } & Urban & 4 & 8 & 0 & 0.084 & 0.773 & 1 & NS* \\
\hline & Rural & 11 & 27 & 0 & & & & \\
\hline $\begin{array}{c}\text { Any previous } \\
\text { exposure }\end{array}$ & Yes & 0 & 0 & 0 & - & - & - & - \\
\hline
\end{tabular}


Comparison of Area Wise Pre-test Knowledge Level and Post-test Knowledge Level of Study Subjects Regarding Management of Selected Obstetric Emergencies

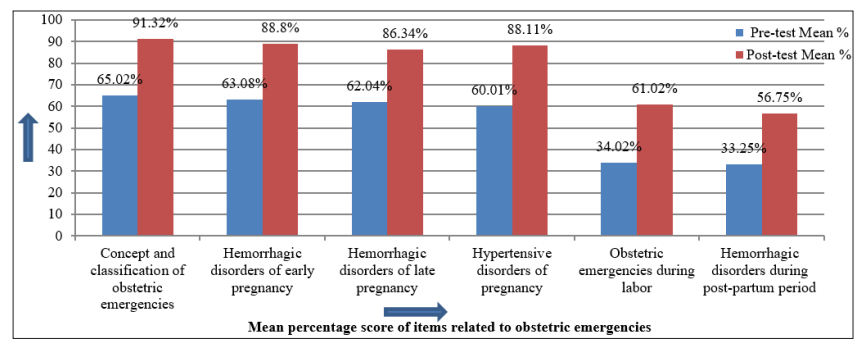

The data presented in the Table 3, showed that there was no significant association between pre-test knowledge level of study subjects and the selected demographic variables like gender, residence and any previous exposure. Hence the researcher failed to reject the null Hypothesis (H02), which states that there is no significant association between pretest knowledge level and selected demographic variables such as gender $(p=0.216)$, residence $(p=0.773)$ and any previous exposure at the significant level of 0.05 .

\section{Discussion}

In present study the pre-test knowledge level, out of 50 study subjects, majority of study subjects $(70 \%)$ had average knowledge, 30\% had Poor knowledge and none of the study subjects had good knowledge.

The findings are supported by a pre-experimental study conducted by Heikham R among the 50 Final Year GNM Students of Selected School of Nursing Belgaum, Karnataka on effectiveness of Planned Teaching Programme (PTP) on Knowledge Regarding Management of Selected Obstetric Emergencies. The study results revealed that in pre-test $60 \%$ had average knowledge, $40 \%$ had poor knowledge and none of the study subjects had good knowledge.

These findings are also supported by a descriptive study conducted by Kavitha $\mathrm{P}^{10}$ among 60 staff nurses on management of obstetrical emergencies at Orotta National Referral Maternity Hospital to assess the level of knowledge of regarding management of obstetrical emergencies. The results of the study showed that majority (65\%) of the staff had moderately adequate knowledge, $35 \%$ of the staff had adequate knowledge.

In the present study, the post-test knowledge level, out of 50 study subjects majority of the study subjects (88\%) had good knowledge, $12 \%$ had average knowledge and none of the study subjects had poor knowledge.

The findings are supported by a study conducted by Pushpamala and Siah ${ }^{11}$ among 60 B.Sc. nursing $3^{\text {rd }}$ year nursing students in selected colleges at Tamil Nadu to assess the effectiveness of video assisted teaching program regarding management of selected obstetric emergencies. Results showed that in post-test majority (80\%) of the study subjects had good knowledge, $20 \%$ of the study subjects had average knowledge and none of the study subjects had poor knowledge.

These findings are also supported by a study conducted by Jayanthi ${ }^{12}$ among 120 staff nurses working in Govt. Hospital Women and children, Egmore, Chennai to assess the effectiveness of structured teaching programme on Antepartum Hemorrhage Results showed that in post-test $80 \%$ the respondents had adequate knowledge and $20 \%$ of respondents had moderate knowledge.

In the present study while comparing the pre-test and post-test knowledge level of study subjects regarding management of selected obstetric emergencies The mean post-test knowledge level of the study subjects regarding management of selected obstetric emergencies is significantly higher $(53.2 \pm 0.832)$ than that of the mean pre-test knowledge level $(25.7 \pm 0.956)$ at 0.05 level of significance.

Danasu $\mathrm{R}^{13}$ Conducted a pre-experimental study among 30 staff nurses at Sri Manakula Vinayagar Medical College and Hospital. The study findings revealed that out of 30 staff nurses, the mean pre- test score was 42.60 and the post-test mean score was 88.23 . The study findings concluded that the training programme on management of selected obstetrical emergencies was effective in improving knowledge among staff nurses Crofts JF ${ }^{14}$ conducted a pre-experimental study among 140 medical graduate's sin Bristol Medical Simulation Centre, England to assess the effectiveness of obstetric emergency training programme. The result of the study showed significant difference between pre-test and posttest. Post-test knowledge score was 23.1 as compared to pre-test score, which was $18.1(p<0.001)$.

In the present study, it was found that there is no significant association between pre-test knowledge level and selected demographic variables like gender, residence and any previous exposure and The findings are supported by a study conducted by Heikham $\mathrm{R}^{9}$ among the 50 Final Year GNM Students of Selected School of Nursing Belgaum, Karnataka on effectiveness of Planned Teaching Programme (PTP) on Knowledge Regarding Management of Selected Obstetric Emergencies. Findings related to the association between the pre-test knowledge scores of Final year GNM students and selected demographic variables revealed that there was no association between the knowledge level and gender of the Final year GNM students.

These findings are supported by a study conducted by Mathew ${ }^{15}$ among 30 Junior Health Assistant Female) Students in selected Training Center Raichur to assess the effectiveness of Structured Teaching Programme on 
knowledge regarding selected obstetric emergencies and their management. No significant association was found between pre-test knowledge scores of the sample with demographic characteristics like exposure to obstetric emergencies during clinical postings and any previous Sources of information.

\section{Conclusion}

Nursing students form an integral and important component of maternal health care delivery system and their contribution in the event of complication as a part of team can be of paramount significance. The education and skill of a student nurse is designed to enable her fulfil their wide and varied role. The aim of developing structured teaching programme for student nurses is to prepare them for occupying the first-level position in nursing in all kinds of health care setting for better maternal outcome.

\section{Conflict of Interest: None}

\section{References}

1. Kildea S, Kruske S, Bowell L. Maternity emergency care: short course in maternity emergencies for remote area health staff with no midwifery qualification. Aust J Rural Health 2006; 14(3): 111-115.

2. Iyengar K, Iyengar SD. Research needs in maternal morbidity. Action Research and Training for Health, Udaipur, India. 2004.

3. World Health Organisation. The Word Health report: Making every mother and child count. Geneva. 2015.

4. World health organization. The World fact Book. 2013. Available from: http//www.cia.gov/library/ publications/the-worldfactbook/geos.

5. WHO, UNICEF, UNFPA. The World Bank: Trends in maternal mortality. 2007.

6. Campbell S, Lee C. Obstetric emergencies: Obstetrics by ten teachers. 17th ed. Arnold Publishers, London. 2000; 303-317.

7. One Step for Women, Ten Steps for a Nation. Available from: https://www.kashmirforum.org/one-step-forwomen-ten-steps-for-nation/.

8. Jha M. A descriptive study to assess maternal mortality in Jammu and Kashmir. International Journal of Community Medicine and Public Health 2015; 19(30): 1056-1059.

9. Heikham GC, Raddi SA. Effectiveness of Planned Teaching Programme (PTP) on Knowledge Regarding Management of Selected Obstetric Emergencies among the Final Year GNM Students of Selected School of Nursing, Belgaum, Karnataka- One Group Pretest Post Test Pre Experimental Study. International Journal of Science and Research 2015; 4(3): 1336-1340.

10. Kavitha P, Tesfay A, Prasath R et al. A study to assess level of knowledge of staff nurses on emergency obstetric management at Orotta national referral maternity hospital. Int J of Allied Med Sci Clin 2014; 2(4): 287-293.

11. Ramaiah P, Siah N. A study to assess the effectiveness of video assisted teaching program regarding management of selected obstetric emergencies among BSC nursing students. BJOG 2015; 113(2): 177-182.

12. Jayanthi. A study to assess the effectiveness of STP on ante-partum haemorrhage among staff nurses. International journal of Applied Research 2013; 4(3): 164-167.

13. Danasu R. A study to assess the effectiveness of skill training programme on management of selected obstetrical emergencies among staff nurses. International Journal of Research \& Review 2013; 274(11).

14. Crofts JF, Bartlett C, Ellis D et al. Training for obstetrical emergencies: A trial of simulation using low-fidelity and high-fidelity mannequins. Obstet. Gynecol 2012; 108(6): 1477-1485.

15. Mathew S. A study to assess the effectiveness of Structured Teaching Programme on knowledge regarding selected obstetric emergencies and their management. International Journal of Multidisciplinary Research 2018; 3(6): 62-72. 